\title{
Pulsatile ocular blood flow investigation in asymmetric normal tension glaucoma and normal subjects
}

\author{
Luigi Fontana, Darmalingum Poinoosawmy, Catey V Bunce, Colm O’Brien, \\ Roger A Hitchings
}

Glaucoma Unit, Moorfields Eye

Hospital, London

L Fontana

D Poinoosawmy

R A Hitchings

Department of Cardiovascular and

Respiratory Sciences,

University "La

Sapienza", Rome, Italy

L Fontana

Department of

Ophthalmology,

Catholic University,

Rome, Italy

L Fontana

Glaxo Department of Ophthalmic

Epidemiology,

Moorfields Eye

Hospital, London

C V Bunce

Princess Alexandra Eye Pavilion, Royal Infirmary, Edinburgh C O’Brien

Correspondence to: Roger A Hitchings, Glaucoma Unit, Moorfield Eye Hospital, City Road, London EC1V 2PD.

Accepted for publication 3 February 1998

\begin{abstract}
Aims-This study was designed to investigate pulsatile ocular blood flow (POBF) in normal tension glaucoma (NTG) patients and in normal controls. NTG patients with unilateral field loss were evaluated to compare POBF values between eyes with and without field loss.

Methods-POBF measurements from more than 1500 subjects were collected during a period of 6 months from six optometric centres. Subjects with systemic vascular diseases (such as systemic hypertension and diabetes), ophthalmic diseases, a positive family history of glaucoma, and those individuals receiving treatment with systemic $\beta$ blockers were excluded on the basis of a questionnaire. For comparison, 95 NTG patients with unilateral field loss, selected from 403 consecutive patients with NTG, underwent POBF testing. For each individual age, sex, intraocular pressure, refraction, and pulse rate were entered into a database.

Results-Data from 777 subjects were included in the analysis. POBF measurements of patients and subjects were compared allowing for differences in age, sex, intraocular pressure, refraction, and pulse rate. POBF was significantly lower in eyes of NTG patients with and without field loss $(p<0.001$ and $p=0.01$ respectively). Eyes of NTG patients with field loss showed significantly lower POBF than the contralateral eyes with normal field ( $\mathrm{p}<0.001)$.

Conclusions-POBF was significantly lower in eyes of NTG patients with and without field loss than in normal subjects, suggesting that differences in ocular blood perfusion are relevant to the development of NTG and are detectable from the early stage of the disease. Furthermore, the finding of lower POBF in NTG eyes with field loss than in the contralateral eyes with normal field suggests that haemodynamic differences between fellow eyes contribute to determine the side of onset of the disease.
\end{abstract}

(Br f Ophthalmol 1998;82:731-736)

Normal tension glaucoma (NTG) is a subset of primary open angle glaucoma (POAG) accounting for up to $35 \%$ of the open angle glaucoma diagnosis. ${ }^{1-3}$ Although the pathogenesis of POAG is still unclear, intraocular pressure (IOP) is considered to be a major risk factor for the development of the disease. ${ }^{4}$ In NTG, where by definition the IOP is within the statistically normal limits, other factors, mainly of vascular origin, have been proposed for the pathogenesis. ${ }^{5}$ Systemic hypotension, ${ }^{7}$ cardiovascular disease,${ }^{58}$ vasospasm, ${ }^{9}$ and rheological alterations (that is, increased plasma viscosity and hypercoagulable state $)^{10}$ have been reported to occur more frequently in NTG patients than in normal subjects, suggesting that in NTG chronic ischaemia may be responsible for the damage to the optic nerve head. Evidence of delayed arteriovenous passage time and capillary filling defects, provided by angiographic studies, supports the concept of reduced vascular perfusion of the optic nerve head in patients with POAG. ${ }^{11} 12$

In recent years, with the development of non-invasive techniques for ophthalmic haemodynamic investigation, ${ }^{13}{ }^{14}$ increasing interest has been directed at the quantitative assessment of the ocular blood flow in glaucoma. One of these techniques is based on continuous IOP recording by means of a pneumotonometer allowing the measurement of the pressure wave (pulse amplitude) of the ocular pulsation during a cardiac circle. This technique, described by Langham and colleagues ${ }^{15-17}$ derives blood flow measurements from a pressure/volume relation ${ }^{18}$ allowing the measurement of the pulsatile component of the ocular blood flow that accounts for $75 \%$ to $85 \%$ of the total blood flow. ${ }^{16}{ }^{19}$ Pulsatile blood flow is mainly determined by the choroidal circulation and the contribution of the retinal circulation is almost negligible. ${ }^{19}$ This is relevant in the investigation of ocular haemodynamics in glaucomatous patients, as the posterior ciliary arteries, responsible for the blood supply to the choroidal circulation, also represent the main arterial vascular supply to the anterior optic nerve. ${ }^{20}$

The aim of this study was to investigate differences in ocular blood perfusion by means of POBF in normal subjects and normal tension glaucoma (NTG) patients. NTG patients with unilateral field loss were selected for this study so that the relation between the onset of field loss and potential disturbances in ocular blood flow could be investigated. In addition, the influence of several clinical factors on POBF was assessed. 
Materials and methods

Basic fundamentals of POBF are given elsewhere. ${ }^{21}{ }^{22}$ In brief, the pulsatile component of choroidal circulation is calculated from the ocular pulse measured by an applanation pneumotonometer. During asystole, a quantity of blood (bolus) enters the choroidal circulation, causing a change in IOP proportional to its volume. A formula is applied to calculate the pulsatile ocular blood flow from the pulse amplitude. For this study we employed the OBF system (OBF Labs Ltd) using software version 3.01. This is similar to the Langham ocular blood flow system, but allows a more objective automatic calculation of the POBF. A pneumotonometer transmits IOP change signals recorded over a period of 5-20 seconds to a computer that automatically selects five pulses of equivalent amplitude. These are taken as the pulse amplitude pattern "representative" for the subject examined. Recorded pulses that do not approximate this pattern are automatically discarded by the software. POBF measurements are derived using a formula that takes into account the cardiac cycle and a standard scleral rigidity. POBF measurements, using the OBF system, are reported to be consistent and reproducible. ${ }^{2324}$

A multicentre study was conducted to collect POBF values of normal subjects and to assess the influence of age, sex, IOP, refractive error, and pulse rate on POBF measurements. Six ophthalmic optometric centres based in different geographic regions within the United Kingdom volunteered to take part in this study. Following practical training on POBF measuring, each optometric centre received an $\mathrm{OBF}$ system for a period of approximately 6 months. During this period 1502 consecutive subjects, attending their local optician for routine appointments, were examined. Subjects underwent pneumotonometry as part of an ophthalmic examination. Informed consent was obtained before POBF testing. Before the test a questionnaire was administered to each volunteer, collecting information on ocular history (that is, ocular diseases, ocular treatments, and previous ocular surgery), a glaucoma family history, medical history (that is, systemic hypertension, diabetes, vascular diseases) and medical treatments, with specific reference to systemic $\beta$ blockers. For each volunteer, age, sex, and refraction were entered in a data base. POBF testing was conducted in the sitting position, with the pneumotonometer probe mounted on a slit lamp microscope, following the instillation of a topical anaesthetic (oxybuprocaine $0.4 \%$ ). Both eyes of each subject were tested following a right before left eye sequence. $\mathrm{OBF}$ software automatically calculated and stored in a database the IOP, pulse amplitude, pulse rate, and POBF values recorded over a maximum period of 20 seconds. If during this time five pulses of equivalent amplitude were not recorded, the test was automatically interrupted and the measurements recorded were classified as "poorly reliable".
For comparison 95 NTG patients (190 eyes) with unilateral field loss were prospectively selected from a cohort of 403 consecutive diagnoses of NTG made at Moorfields Eye Hospital between 1986 and 1996. The diagnosis of NTG was made if the patient had an untreated IOP $\leqslant 21 \mathrm{~mm} \mathrm{Hg}$ at diurnal phasing (at least eight readings, allowing a single IOP reading not greater than $23 \mathrm{~mm} \mathrm{Hg}$ ), a reproducible visual field defect typical of glaucoma (retinal nerve fibre layer type), glaucomatous optic nerve head cupping, and open angles at clinical examination. Visual field testing was carried out using the 24-2 program of the Humphrey visual field analyser (HFA) (Humphrey Instruments Inc, Palo Alto, CA, USA). Inclusion criteria for this study were the presence of a reproducible field defect in one eye and a consistently normal field in the fellow eye, absence of concomitant ocular diseases, previous ocular surgery, and medical treatment with systemic $\beta$ blockers. No patient was on topical or systemic treatment for glaucoma at the time of POBF testing. Normal 24-2 HFA visual field was defined using STATPAC-2 software (Humphrey Instruments Inc, Palo Alto, CA, USA). Criteria for the definition of a normal field were absence of one or more clusters of three or more neighbouring locations showing sensitivity loss of $\geqslant 5 \mathrm{~dB}$ below the age matched Humphrey normal data base, or of a single location with a sensitivity loss $\geqslant 10 \mathrm{~dB}$ in each hemifield. Three consecutive series of POBF measurements (using OBF system, software version 3.01, OBF Labs Ltd) were recorded by a single experienced operator (DP) for each NTG patient, at the time of last visual field test. POBF was measured in the sitting position with the pneumotonometer mounted on slit lamp microscope, after instillation of a topical anaesthetic (oxybuprocaine $0.4 \%)$. Eyes were tested following a right before left eye sequence. The median POBF and IOP values were used for the analysis. For each NTG patient the following information was entered in a database; the mean defect (MD) and the corrected pattern standard deviation (CPSD) values of the last HFA 24-2, the mean value of the diurnal IOP curve and the refraction.

All analysis were conducted using SPSS (version 7.0). The relation between POBF and each of age, sex, IOP, refraction, and pulse rate in normal subjects was investigated using a linear regression technique (uni- and multivariate). Age, IOP, refraction, and pulse rate were analysed as continuous variables, while sex was studied as a categorical variable. Right and left eyes were analysed separately. To effect normality of the data, POBF was log transformed. To determine whether POBF differs between NTG patients and normal subjects by use of multivariate regression techniques, one eye was then selected at random, from each normal subject, making adjustments for factors found to be influential on POBF in the first part of the analysis. The eyes from NTG patients with and without visual field loss, were examined separately. 


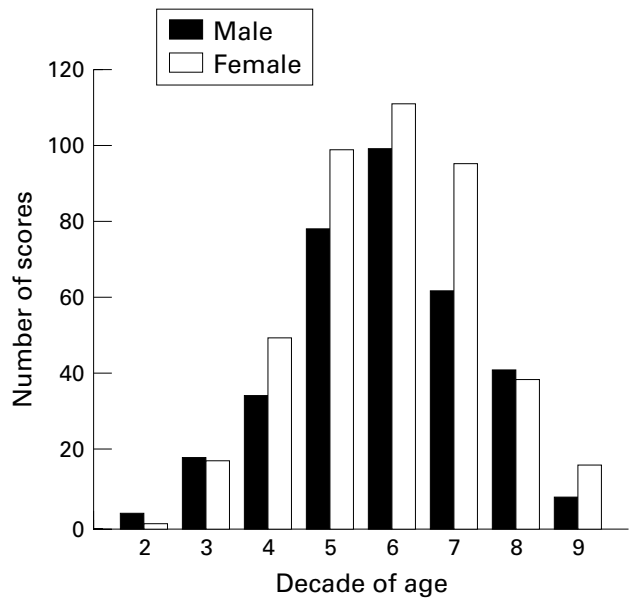

Figure 1 Normal subjects $(n=777)$. Age and sex distribution.

The association between onset of visual field loss and ocular blood flow was explored by comparing POBF, IOP (mean of diurnal curve), and refraction of fellow eyes of NTG patients, using the Wilcoxon matched pairs test. For all analyses $\mathrm{p}<0.05$ was taken as statistically significant.

\section{Results}

Of the 1502 subjects who underwent POBF investigation, $563(37 \%)$ were excluded from the analysis on the basis of one or more positive answers in the questionnaire. POBF from 162 $(11 \%)$ subjects were also excluded as their measurements were classified as "poorly reliable" by the OBF software. Data from the remaining 777 (1554 eyes) subjects were used for the analysis.

The age and sex distribution for the normal subjects is shown in Figure 1: 347 (45\%) were

Table 1 Normal subjects. Median (IQ) of IOP, refraction, and POBF for right and left eyes

\begin{tabular}{lll}
\hline & RE median $(I Q)$ & LE median $(I Q)$ \\
\hline IOP $(\mathrm{mm} \mathrm{Hg})$ & $16.3(14.3,18.7)$ & $15.9(13.7,18.5)$ \\
Refraction $(\mathrm{D})$ & $0.25(-0.25,1.25)$ & $0.25(-0.5,1.25)$ \\
POBF $(\mu 1 / \mathrm{min})$ & $810(647.5,1013.5)$ & $838(647,1046)$ \\
\hline
\end{tabular}

Table 2 Normal subjects right eyes. Univariate and multivariate regression analyses

\begin{tabular}{lclcl}
\hline Independent variables & $\begin{array}{l}\text { Unadjusted } \\
\text { coefficient }\end{array}$ & $\begin{array}{l}\text { Unadjusted 95\% } \\
\text { confidence intervals }\end{array}$ & $\begin{array}{l}\text { Adjusted } \\
\text { coefficient }\end{array}$ & $\begin{array}{l}\text { Adjusted 95\% } \\
\text { confidence intervals }\end{array}$ \\
\hline Age (years) & $-0.0035^{\star}$ & $(-0.005,-0.002)$ & $-0.0047^{\star}$ & $(-0.006,-0.003)$ \\
Sex & $0.176^{\star}$ & $(0.129,0.224)$ & $0.175^{\star}$ & $(0.133,0.217)$ \\
IOP (mm Hg) & $-0.029^{\star}$ & $(-0.035,-0.024)$ & $-0.027^{\star}$ & $(-0.032,-0.022)$ \\
Refraction (D) & $0.044^{\star}$ & $(0.033,0.055)$ & $0.05^{\star}$ & $(0.04,0.059)$ \\
Pulse rate (beats/min) & $0.0036^{\star}$ & $(0.002,0.005)$ & $0.0043^{\star}$ & $(0.003,0.006)$ \\
\hline
\end{tabular}

${ }^{\star} \mathrm{p}<0.001$.

Dependent variable log POBF. Independent variables age, IOP, refraction, and pulse rate were introduced as continuous. Sex was analysed as categorical variable, $1=$ male; $2=$ female.

Table 3 Normal subjects. POBF values for men and women by decades of age

\begin{tabular}{lclrl}
\hline Age decade & No of men & $\begin{array}{l}\text { POBF }(\mu \mathrm{l} / \mathrm{min}) \\
\text { median }(I Q)\end{array}$ & $\begin{array}{l}\text { No of } \\
\text { women }\end{array}$ & $\begin{array}{l}\text { POBF }(\mu \mathrm{l} / \mathrm{min}) \\
\text { median }(I Q)\end{array}$ \\
\hline 2 & 4 & $697(344.5,884.5)$ & 1 & - \\
3 & 19 & $925(649,1040)$ & 18 & $922.5(659.25,1132.5)$ \\
4 & 35 & $763(704,923)$ & 50 & $875.5(676.25,1046)$ \\
5 & 79 & $748(633,908)$ & 99 & $1020(773,1253)$ \\
6 & 99 & $720(580,915)$ & 111 & $874(676,1068)$ \\
7 & 62 & $712(614.75,875)$ & 95 & $830(733,1004)$ \\
8 & 41 & $713(567.5,916)$ & 39 & $770(618,892)$ \\
9 & 8 & $539(373.5,772.75)$ & 17 & $801(561,947)$ \\
\hline
\end{tabular}

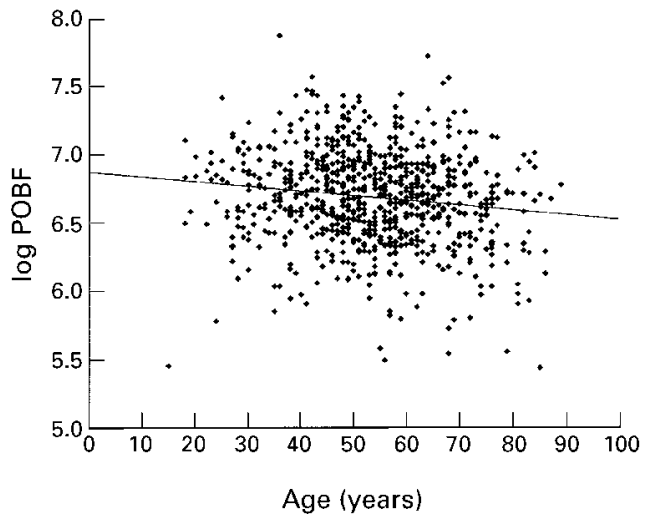

Figure 2 Normal subjects, right eyes. Scattergram and linear regression analysis of the distribution of $\log P O B F v$ age $\left(n=777 ; r=0.142 ; r^{2}=0.020 ; p<0.0001\right)$.

men and $430(55 \%)$ were women. The mean age was 53.03 (SD 14.19) and 53.87 (13.96) years for men and women respectively. IOP, refraction, and POBF measurements are summarised separately for right and left eyes in Table 1.

The relation between POBF and each of the clinical variables-age, sex, IOP, refraction, and pulse rate was assessed using linear regression analysis (Table 2). Factors were first fitted in a univariate model, then all those significant at $p<0.05$ were fitted in a multivariate model to assess independence of effects. A weak but statistically significant reduction of POBF with increasing age was found ( $p$ $<0.001$ ) (Fig 2). This was seen in both sexes (Fig 3). Overall, women showed higher POBF values than men. The median (interquartile range) (IQ) POBF was $886(696 ; 1089) \mu \mathrm{l} / \mathrm{min}$ for women and $731(605 ; 913) \mu \mathrm{l} / \mathrm{min}$ for men ( $\mathrm{p}<0.001)$. POBF values by decades are represented separately for men and women in Table 3. The median (CI) pulse rate was 70 $(63 ; 78)$ beats/min and $74(67 ; 82)$ beats $/ \mathrm{min}$ for men and women respectively $(\mathrm{p}<0.001)$. A weak although statistically significant rise in POBF was seen by increasing heart frequency $(r=0.153 ; \mathrm{p}<0.001)$. In $114(15 \%)$ subjects the IOP was greater than $21 \mathrm{~mm} \mathrm{Hg}$ in at least one eye and in $29(4 \%)$ was greater than 25 $\mathrm{mm} \mathrm{Hg}$. The results suggest decreasing POBF by increasing IOP values $(r=0.331 ; \mathrm{p}<0.001)$. In $56 \%$ of subjects the refractive error comprised plus or minus 1 dioptre (sphere equivalent): 127 (16\%) were myopic more than 1 dioptre (sphere equivalent) and 215 (28\%) hypermetropic more than 1dioptre (sphere equivalent). Ocular blood flow decreased with increasing myopic refractive error $(r=0.278 ; \mathrm{p}<0.001)$.

Of the 95 NTG patients with unilateral field loss selected for this study, 35 (37\%) were male and $60(63 \%)$ female. The median (IQ) age was $65(56 ; 71)$ years for men and 65 (59.5; 73.2) years for women. The side of field loss was in the left eye in $57(60 \%)$ patients. IOP, refraction, and POBF values are shown separately for eyes with and without field loss in Table 4. Mean diurnal IOP was significantly higher in the eye with field loss $(p<0.001)$, although the difference between fellow eyes 


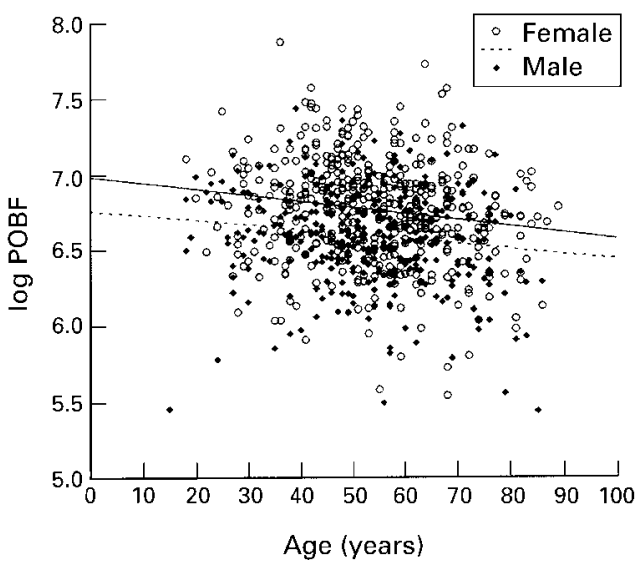

Figure 3 Normal subjects. Scattergram and linear regression analysis of the distribution of $\log P O B F v$ age for men and women $\left(n=345 ; r=0.140 ; r^{2}=0.020 ; p=\right.$ 0.009 for men and $n=430 ; r 0.166 ; r^{2}=0.028 ; p=0.001$ for women).

was clinically small. POBF was significantly lower in the eye with field loss $(p<0.001)$. Difference in refractive error between fellow eyes was not significant $(\mathrm{p}=0.193)$.

Multivariate regression analysis was used to assess any difference between POBF measurements of NTG and normal subjects allowing for differences in age, sex, IOP, refraction, and pulse rate. The multivariate model was fitted using a categorical variable, taking value 0 if normal, 1 if NTG. Data from NTG eyes with normal field and with field loss were analysed separately (Tables 5 and 6). Compared with normal subjects, NTG patients showed lower

Table 4 NTG patients. Median (IQ) of MD, CPSD, IOP, refraction, and POBF for eyes with and without field loss

\begin{tabular}{llll}
\hline & $\begin{array}{l}\text { Normal field } \\
\text { median }(I Q)\end{array}$ & $\begin{array}{l}\text { Abnormal field } \\
\text { median }(I Q)\end{array}$ & p Value \\
\hline MD (dB) & $-1.28(-2.16,0.43)$ & $-8.47(-12.49,-5.56)$ & - \\
CPSD & $1.84(1.18,2.5)$ & $11(7.35,13)$ & - \\
IOP mean (mm Hg) & $16.1(14.8,17.8)$ & $16.8(15.6,18.6)$ & $<0.001$ \\
Refraction (D) & $0(-1.18,1.75)$ & $0(-1.5,1.5)$ & 0.193 \\
POBF $(\mu \mathrm{l} / \mathrm{min})$ & $718.67(559,874.67)$ & $676.67(508,818)$ & $<0.001$ \\
\hline
\end{tabular}

Table 5 Multivariate regression analysis. Dependent variable log POBF

\begin{tabular}{lccl}
\hline Independent variables & Coefficient & p Value & $95 \%$ Confidence intervals \\
\hline Age (years) & -0.0046 & $<0.001$ & $(-0.006,-0.003)$ \\
Sex & 0.170 & $<0.001$ & $(0.131,0.21)$ \\
IOP (mm Hg) & -0.027 & $<0.001$ & $(-0.032,-0.022)$ \\
Refraction (D) & 0.049 & $<0.001$ & $(0.041,0.058)$ \\
Pulse rate (beats/min) & 0.0038 & $<0.001$ & $(0.002,0.005)$ \\
NTG eyes normal field & -0.099 & 0.007 & $(-0.17,-0.027)$ \\
\hline
\end{tabular}

Independent variables age, IOP, refraction, and pulse rate were introduced as continuous. Sex was analysed as categorical variable, $1=$ male; $2=$ female. NTG was introduced as dichotomous variable; $0=$ normal, $1=$ NTG. Adjusted $r^{2}=0.291$, residual $\mathrm{SD}=0.007$.

Table 6 Multivariate regression analysis. Dependent variable log POBF

\begin{tabular}{lcll}
\hline Independent variables & Coefficient & $p$ Value & 95\% Confidence intervals \\
\hline Age (years) & -0.0047 & $<0.001$ & $(-0.006,-0.003)$ \\
Sex & 0.17 & $<0.001$ & $(0.13,0.21)$ \\
IOP (mm Hg) & -0.027 & $<0.001$ & $(-0.032,-0.022)$ \\
Refraction (D) & 0.051 & $<0.001$ & $(0.042,0.059)$ \\
Pulse rate (beats/min) & 0.004 & $<0.001$ & $(0.003,0.005)$ \\
NTG eyes abnormal field & -0.165 & $<0.001$ & $(-0.238,-0.092)$ \\
\hline
\end{tabular}

Independent variables age, IOP, refraction and pulse rate were introduced as continuous. Sex was analysed as categorical variable, $1=$ male; $2=$ female. NTG was introduced as dichotomous variable; $0=$ normal, $1=\mathrm{NTG}$. Adjusted $r^{2}=0.313$, residual $\mathrm{SD}=0.0072$. values of $\mathrm{POBF}$ in eyes with normal field $(\mathrm{p}=$ $0.007)$ and with field loss $(p<0.001)$.

\section{Discussion}

Studies investigating ocular haemodynamics are influenced by several variables assuming a critical relevance when measurements of different subjects are compared. Using uni- and multivariate regression analysis we investigated the independent effect of age, sex, IOP, refraction, and pulse rate on POBF. The results indicate a progressive reduction of POBF by increasing age of the subjects examined, confirming the decline of ocular perfusion in the elderly described in studies based on $\mathrm{POBF}^{25}$ and colour Doppler imaging $(\mathrm{CDI})^{26}$ investigations. A similar influence of age on POBF was seen in both sexes, although POBF was found to be approximately $18 \%$ higher in women than in men. Some of this difference may be attributed to the higher heart rate found in women this study. This finding is supported by a previous report of a sex related difference in POBF in normal subjects. ${ }^{24}$ Variations in ocular volume, scleral rigidity, or ocular perfusion may contribute to differences in pulse amplitude in subjects with ametropias. ${ }^{27}$ Lower POBF was seen in subjects with myopic refraction, confirming the relation between refractive error and amplitude of the ocular pulse described by James et $a l^{28}$ Intraocular pressure is a variable involved in the calculation of $\mathrm{POBF}^{18}$; IOP rise is accompanied by decreased POBF values in NTG patients and normal controls. ${ }^{29}$ Although the IOP range of the subjects investigated in this study was limited, a distinctive trend for decreasing POBF with increasing IOP values was noticed.

All these variables contribute to the remarkable interindividual difference in POBF values seen among the normal subjects investigated in this study (Fig 2). In our analysis the effect of systemic blood pressure on POBF was not investigated. Although the influence of blood pressure on ocular blood flow can not be excluded, effort was made to recruit only subjects with no known systemic hypertension or other vascular diseases. Previous study investigating POBF in normotensive normal subjects have found no association between POBF and systemic blood pressure. ${ }^{24}$

Using multivariate regression analysis POBF measurements of normal subjects and NTG patients with unilateral field loss were compared allowing for differences in age, sex, refraction, and IOP between patients and controls. The analysis was carried out including in the model POBF data relative to the NTG eyes with field loss and with normal field separately. The results showed significantly lower POBF values in eyes of NTG patients with and without field loss compared with normal controls, indicating substantial differences in ocular blood perfusion between the two groups. Our findings are consistent with those of previous studies investigating ocular haemodynamics in NTG patients and normal subjects by means of $\mathrm{POBF}^{29-31}$ and CDI of the ophthalmic artery. ${ }^{32-38}$ It is important to emphasise that this 
study was based on a large number of consecutive subjects attending their local optician for routine refractive examination. Opticians who volunteered to participate to this study were trained on measuring POBF using the OBF system. Subjects with an ophthalmic history or with a family history of glaucoma or with known systemic hypertension or other vascular pathologies were excluded from the analysis. It seems reasonable to consider that POBF values provided in this study may be representative for normal subjects. Our POBF values were similar to the ones reported in previous studies ${ }^{19} 29$ when comparing subjects of the same age group and sex. ${ }^{24}$ Overall, analysis by decades (Table 3) showed consistently higher POBF values than the ones reported by Ravalico et $a l^{25}$ in a study investigating POBF changes with age. Some of the differences may be explained by the higher proportion of males investigated compared with our study.

Comparison was made with a group of NTG patients selected from a large cohort of consecutive cases of NTG followed at Moorfields Eye Hospital. Patients presented homogeneous characteristics with respect to visual field damage and treatment for glaucoma. Unilateral field loss cases were selected for this study to investigate the role of blood flow in relation to field asymmetry. Optic nerve head appearance was not considered for the analysis. As optic disc cupping may precede visual field changes, ${ }^{39} 40$ it is possible that a proportion of our patients with unilateral field loss may have had bilateral disc cupping. Statistically lower POBF was found in eyes with established field loss than their fellow eyes with normal field, suggesting that circulatory abnormalities are associated with the asymmetric onset of visual field loss and differences in vascular perfusion between fellow eyes may be relevant to determine the side of onset of field damage. However, it is important to consider that the IOP may also represent an important lateralising factor in field asymmetry. ${ }^{41}{ }^{42}$ In our study the mean value of the IOP diurnal curve was statistically higher in the eyes with field damage although the difference between fellow eyes was clinically small.

In conclusion, this study provides further evidence of reduced ocular perfusion in patients with NTG compared with normal subjects, supporting the role of ocular blood flow in the development of the disease. In addition, we showed that in NTG patients with unilateral field loss lower POBF values were found not only the with field damage, but also in the fellow eyes with normal field, suggesting that haemodynamic changes may precede glaucomatous field loss onset.

Each author states that he/she has no proprietary interest in the development or marketing of any product or instrument mentioned in this article.

1 Shiose Y, Kitazawa Y, Tsukahara S, et al. Epidemiology of glaucoma in Japan. A nationwide glaucoma survey. $\mathscr{f p n} \mathcal{F}$ Ophthalmol 1991;35:133-55.

2 Sommer A, Tielsh JM, Katz J, et al. Relationship between intraocular pressure and primary open-angle glaucoma 109:1090-5.
3 Klein BE, Klein R, Sponsel WE, et al. Prevalence of glein BE, Klein R, Sponsel WE, et al. Prevalence of
glaucoma. The Beaver Dam eye study. Ophthalmology
1992;99:1499-504.

4 Jay JL, Murdoch JR. The rate of visual field loss in untreated primary open angle glaucoma. Br F Ophthalmol 1993;77: $176-8$

5 Drance SM, Sweeney VP, Morgan RW, et al. Studies of factors involved in the production of low tension glaucoma. Arch Ophthalmol 1973;89:457-65.

6 Shulzer M, Drance SM, Carter CJ, et al. Biostatistical evidence for two distinct chronic open angle glaucoma populations. Br f Ophthalmol 1990;74:196-200.

7 Graham SL, Drance SM, Wijsman K, et al. Ambulatory blood pressure monitoring in glaucoma. Ophthalmology 1995;102:61-9.

8 Hayreh SS, Zimmerman MB, Podhajsky P, et al. Nocturnal arterial hypotension and its role in optic nerve head and ocular ischaemic disorders. Am f Ophthalmol 1994;117: 603-24.

9 Drance SM, Douglas GR, Wijsman K, et al. Response of blood flow to warm and cold in normal and low-tension glaucoma patients. Am f Ophthalmol 1988;105:35-9.

10 O'Brien C, Butt Z, Ludlam C, et al. Activation of the coagulation cascade in untreated primary open-angle glaucoma. Ophthalmology 1997; 104:725-9.

11 Tuulonen A, Nagin P, Schwartz B, et al. Increase of pallor and fluorescein-filling defects of the optic disc in the follow-up of ocular hypertensives measured by computerized image analysis. Ophthalmology 1987;94:558-63.

12 Wolf S, Arend O, Sponsel WE, et al. Retinal haemodynamics using laser scanning ophthalmoscopy and hemorheology in chronic

13 Williamson TH, Harris A. Ocular blood flow measurement. Br ₹ Ophthalmol 1994;78:939-45.

14 Michelson G, Groh MJM. Methods for the investigation of circulatory changes in glaucoma. Curr Opin Ophthalmol circulatory chan

15 Langham ME, To'mey K. A clinical procedure for measuring the ocular pulse-pressure relationship and the ophthalmic arterial pressure. Exp Eye Res 1987;27:17-25.

16 Langham ME, Farell MA, O'Brien V, et al. Blood flow in the human eye. Acta Ophthalmol 1989;67:9-12.

17 Silver DM, Farrell RA, Langham ME, et al. Estimation of pulsatile ocular blood flow from intraocular pressure. Acta Ophthalmol 1989;191(suppl):25-9.

18 Krakau CET. Calculation of the pulsatile ocular blood flow. Invest Ophthalmol Vis Sci 1992;33:2754-6.

19 Langham ME, Farell MA, O'Brien V, et al. Non-invasive measurement of pulsatile blood flow in the human eye. In: Lambrou GN, Greve EL, eds. Ocular blood flow in glaucoma. 1989:93-9.

20 Onda E, Cioffi GA, Bacon DR, et al. Microvasculature of the human optic nerve. Am f Ophthalmol 1995;120:92-102.

21 Silver DM, Farrell RA. Validity of pulsatile ocular blood flow measurements. Surv Ophthalmol 1994;38(Suppl): flow meast 80 .

22 Krakau CET. A model for pulsatile and steady ocular blood flow. Graefes Arch Ophthalmol 1995;233:112-18.

23 Butt Z, O'Brien C. Reproducibility of pulsatile ocular blood flow measurements. F Glaucoma 1995;4:214-18.

24 Yang YC, Hulbert MFG, Batterbury M, et al. Pulsatile ocular blood flow measurements in healthy eyes: reproducibility and reference values. F Glaucoma 1997;6: 175-9.

25 Ravalico G, Toffoli G, Pastori G, et al. Age related ocular blood flow changes. Invest Ophthalmol Vis Sci 1996;37: 2645-9.

26 Williamson TH, Lowe GDO, Baxter GM. Influence of age, systemic blood pressure, smoking, and blood viscosity on systemic blood pressure, smoking, and blood viscosity on

27 Perkins ES. Ocular volume and ocular rigidity. Exp Eye Res 1981;33:141-5.

28 James CB, Trew DR, Clark K, et al. Factors influencing the ocular pulse. Axial length. Graefes Arch Clin Exp Ophthalmol 1991;229:341-4.

29 Quaranta L, Manni G, Donato F, et al. The effect of increased intraocular pressure on pulsatile ocular blood flow in low tension glaucoma. Surv Ophthalmol 1994; 38(suppl): $S 177-82$.

30 James CB, Smith SE. Pulsatile ocular blood flow in patients with low tension glaucoma. Br F Ophthalmol 1991;75:46670 .

31 Ravalico G, Pastori G, Toffoli G, et al. Visual and blood flow responses in low tension glaucoma. Surv Ophthalmol 1994; 38(Suppl):S173-6.

32 Galassi F, Nuzzacci G, Sodi A, et al. Color doppler imaging in evaluation of optic nerve blood supply in normal and glaucomatous subjects. Int Ophthalmol 1992;16:273-6.

33 Rojanapongpun P, Drance SM, Morrison B. Ophthalmic artery flow velocity in glaucomatous and normal subjects. BrF Ophthalmol 1993;77:25-9.

34 Harris A, Sergott RC, Spaeth GL, et al. Color doppler analysis of ocular vessel blood velocity in normal-tension glaucoma. Am f Ophthalmol 1994;118:642-9.

35 Butt Z, McKillop G, O'Brien C, et al. Measurement of ocular blood flow velocity using colour doppler imaging in low tension glaucoma. Eye 1995;9:29-33.

36 Rankin SJA, Walman BE, Buckley AR, et al. Color doppler imaging and spectral analysis of the optic nerve vasculature in glaucoma. Am f Ophthalmol 1995;119:685-93.

37 Nicolela MT, Drance SM, Rankin SJA, et al. Color doppler imaging in patients with asymmetric glaucoma and unilateral field loss. Am f Ophthalmol 1996;121:502-10. 
38 Kaiser HJ, Schoetzau A, Stumpfig D, et al. Blood-flow velocities of the extraocular vessels in patients with high-tension and normal-tension primary
coma. Am f Ophthalmol 1997;123:320-7.

39 Quigley HA, Addicks EM, Green WR. Optic nerve damage in human glaucoma. III. Quantitative correlation of nerve fiber loss and visual field defect in glaucoma, ischaemic neuropathy, papilledema and toxic neuropathy. Arch Ophthalmol 1982;100:135-46.

40 Caprioli J, Miller JM, Sears M. Quantitative evaluation of the optic nerve head in patients with unilateral visual field loss from primary open angle glaucoma. Ophthalmology 987;94:1484-7.

41 Cartwright MJ, Anderson DR. Correlation of asymmetric damage with asymmetric intraocular pressure in Normal Tension Glaucoma. Arch Ophthalmol 1988;106:898-900.

42 Crichton A, Drance SM, Gordon RD, et al. Unequal intraocular pressure and its relation to asymmetric visual field defects in low-tension glaucoma. Ophthalmology 1989; 96:1312-14. 